\title{
CAMINHOS PARA REPENSAR O CURRÍCULO ESCOLAR: Olhares a Partir das Articulações Ciência, Cultura e Arte
}

\author{
Suiane da Ewerling da Rosa ${ }^{1}$ \\ Itana da Purificação Costa² \\ Lucélia Avelino Gomes ${ }^{3}$
}

\begin{abstract}
RESUMO
Este trabalho apresenta um estudo sobre teorias de currículo e suas contribuições para repensar configurações curriculares no Ensino de Ciências. Para essa construção, destacamos a abordagem temática como pressuposto orientador, entendendo que ela é uma perspectiva potencializadora diante das limitações presentes nos currículos tradicionais. Dessa maneira, o objetivo é promover análises crítico-reflexivas sobre o campo curricular e suas implicações e possíveis intervenções para o Ensino de Ciências. $O$ trabalho trata-se de uma investigação qualitativa e de cunho teórico e propositivo. Dentre os resultados, destacamos caminhos para repensar configurações curriculares fundamentadas pelas articulações ciência, cultura e arte. Como contribuição para a área, propomos diálogos que sinalizem limitações e potencialidades desse repensar, tendo em vista propósitos educacionais alicerçados por uma formação mais humana e crítica.
\end{abstract}

Palavras-chave: Ensino de Ciências. Currículo. Artes. Interdisciplinaridade.

\section{WAYS TO RETHINK THE SCHOOL CURRICULUM: LOOKS FROM THE ARTICULATIONS SCIENCE, CULTURE AND ART}

\section{ABSTRACT}

This paper presents a study on curriculum theories and their contributions to rethinking curricular configurations in Science Teaching. For this construction, we highlight the thematic approach as a guiding assumption understanding that it is a potentiating perspective in view of the limitations present in traditional curricula. Thus, the objective is to promote critical-reflexive analyses on the curricular field and its implications and possible interventions for Science Teaching. The work is a qualitative investigation of a theoretical and propositional nature. Among the results, we highlight ways to rethink curricular configurations based on the articulations of science, culture and art. As a contribution to the area, we propose dialogues that signal limitations and potentialities of this rethink, in view of educational purposes based on a more human and critical formation. Keywords: Science Teaching. Curriculum. Arts. Interdisciplinarity.

RECEBIDO EM: 28/2/2020

ACEITO EM: $1 \% / 6 / 2020$

\footnotetext{
1 Autora correspondente. Universidade Federal do Oeste da Bahia - Ufob. Rua Professor José Seabra de Lemos, 316 - Recanto dos Pássaros. CEP: 47808-021. Barreiras/BA, Brasil. http://lattes.cnpq.br/2349974472232866. https://orcid.org/0000-0001-6476-9386. suiedr@gmail.com

2 Universidade Federal do Oeste da Bahia - Ufob. http://lattes.cnpq.br/2852303436375919. https://orcid.org/0000-0003-0218-933X.

3 Universidade Federal do Oeste da Bahia - Ufob. http://lattes.cnpq.br/3033750379967013. https://orcid.org/0000-0001-9398-4966.
} 
O currículo não possui uma definição universal, pois é interpretado por uma diversidade de aspectos teóricos. Este campo de construção social, no entanto, pode ser visto como caminho, roteiro, estruturação, parte do Projeto Político Pedagógico de uma escola, mas de importância maior ou igual, uma vez que trata das formas que o concretiza. Assim, o currículo não deve ser visto como mera ferramenta burocrático-pedagógica porque, escrito publicamente, indica as aspirações e intenções para a escolarização.

Das definições de currículo, Goodson (2013a) distingue o escrito do currículo da atividade de sala de aula (currículo ativo). O que está escrito não implica, necessariamente, efetivação. Nesse sentido, o currículo pode ser descrito de duas maneiras: como fato e como prática. O primeiro deve ser considerado de forma mais profunda e não apenas como algo superficial do contexto escolar. Trata-se de uma realidade social, historicamente construída; é fato, e não algo mistificado que faz da educação "[...] uma coisa que as pessoas não podem compreender nem controlar" (GOODSON, 2013a, p. 18). Já o currículo como prática envolve as ações e intervenções subjetivas dos sujeitos (professores e estudantes). Também pode haver, no entanto, a mistificação, "[...] impedindo-nos de entender o surgimento e persistência históricos de determinados conceitos, conhecimentos e convenções (como, por exemplo, as matérias escolares)" (YOUNG, 1977 apud GOODSON, 2013a, p. 18). Por isso, o currículo, como fato, corresponde ao estabelecimento intelectual e político passado. É o que está apresentado no currículo escrito. Já o currículo como prática faz concessões, contradiz ou ainda transcende o currículo escrito (GOODSON, 2013a).

Dessa maneira, o currículo (fato/pré-ativo ou prática/ativo) é reflexo da finalidade da escola. Em outras palavras, a escola satisfaz as necessidades históricas de uma sociedade e o seu currículo pode corresponder à hegemonia ou pode ser campo de conflito e se alterar para responder às lutas sociais. Por isso, o currículo deixou de ser apenas uma área técnica; fala-se agora em uma tradição crítica fundamentada por questões sociológicas, políticas e epistemológicas. Ainda, mesmo que os encaminhamentos voltados ao "'como' do currículo continuem importantes, elas só adquirem sentido dentro de uma perspectiva que as considere em sua relação com questões que perguntem pelo 'por quê' das formas de organização do conhecimento escolar" (MOREIRA; TADEU, 2018, p. 13 , grifo do autor).

Considerando que esses direcionamentos são de extrema relevância para orientar outras formas de compreender e construir o currículo, no Ensino de Ciências eles ainda se constituem como desafios. Tradicionalmente, o currículo nessa área "[...] se definiu a partir de conteúdos conceituais organizados de forma linear, buscando reconstruir estaticamente o desenvolvimento daquela ciência que toma por referência" (WATANABE; KAWAMURA, 2017, p. 146). Assim, balizado por essa percepção, tem-se, hegemonicamente, a ideia de currículo como algo dado, pronto, engessado. Ao professor, cabe cumprir programas, vencer conteúdos. Ou seja, os professores da área de Ciências da Natureza "ainda permanecem seguindo os livros didáticos, insistindo na memorização de informações isoladas, acreditando na importância dos conteúdos tradicionalmente explorados e na exposição como principal forma de ensino" (DELIZOICOV; ANGOTTI; PERNAMBUCO, 2011, p. 127). Logo, defendemos outros direcionamentos, e precisamos ir além das formas tradicionais. Os conhecimentos estão disseminados na realidade vi- 
vida; a ciência não está restrita ao espaço escolar, nem aos pesquisadores e pesquisadoras, e, muitas vezes, apresenta-se mais interessante fora dele. Os debates éticos, políticos, sociais, culturais e ambientais estão postos; polêmicas/controversas são criadas; as opiniões estão sendo construídas; mas e a escola?

Buscando, portanto, encaminhamentos para contribuir com esse cenário, propomos dar visibilidade para configurações curriculares que estejam atentas ao "o que e por que ensinar", que incluam aspectos da realidade vivida pelos estudantes, que estejam abertas para as diferentes manifestações socioculturais e contradições vividas. Dessa forma, objetivamos promover discussões crítico-reflexivas sobre o campo curricular e suas implicações e possíveis intervenções para o Ensino de Ciências. Fundamentado por teóricos do campo curricular e de estudiosos que aprofundam e exercitam essas questões na área de Educação em Ciências, apresentamos a abordagem temática (DELIZOICOV; ANGOTTI; PERNAMBUCO, 2011) como pressuposto para repensar o currículo. Para esse exercício, utilizamos a aproximação entre ciência, cultura e arte como motivação; isso porque, ao promover esse diálogo é possível dar abertura para questões em geral silenciadas na área, bem como valorizar experiências e protagonismos, contribuindo, assim, para a constituição de diferentes identidades sociais não restritas pela hegemonia sociocultural.

\section{ENCAMINHAMENTOS METODOLÓGICOS}

Este artigo é oriundo de uma investigação qualitativa que não possui a representatividade numérica de dados como finalidade, e sim explicar e compreender o porquê das coisas, centrando-se nas relações sociais (GERHARDT; SILVEIRA, 2009). De cunho teórico e propositivo, o trabalho foi desenvolvido em três etapas: estudos sobre currículo; aprofundamentos referentes às articulações ciência, cultura e arte; e proposição curricular.

Assim, o trabalho está organizado, inicialmente, pelo desenvolvimento de estudos referentes às teorias de currículo e suas imbricações com a área de Educação em Ciências. Em seguida, apresentamos uma análise de trabalhos da área que possuem articulação com as artes nas suas mais variadas representações. $O$ intuito da análise, além de evidenciar as articulações ciência, cultura e arte, esteve pautado pela investigação de materiais orientadores para a construção de uma proposição curricular. Para essa etapa, foi realizado um levantamento de trabalhos no campo de pesquisas livres da internet, portanto não teve como critério um local específico de busca, como periódicos ou eventos. O objetivo em não delimitar um campo específico de busca esteve centrado na não intencionalidade de realizar uma pesquisa próxima ao denominado estado de conhecimento, mas em investigar materiais de acessibilidade imediata do professor do ensino básico. Ou seja, buscamos situar trabalhos aos quais, em geral, esses professores têm acesso e que podem contribuir para ações didático-pedagógicas.

Assim, no primeiro levantamento foram selecionados 31 trabalhos que corresponderam à identificação "Ensino de Ciências (Física, Química, Biologia), Cultura e Artes". Após essa etapa, foi realizado um novo recorte selecionando trabalhos com maior potencialidade para o desenvolvimento de ações educativas para a educação básica. Desse processo, 15 trabalhos foram selecionados e passaram pela confirmação da sua 
confiabilidade e de relevância em termos de conteúdo do material. Esses trabalhos estão apresentados no Quadro 1, com destaque para as seguintes características: (1) conteúdos, aqui numa perspectiva conceitual descrita nos trabalhos; (2) relação com cultura e arte; e (3) abordagem, como classificação dos textos enquanto uma discussão teórica, que atua como sustentação e justificativa para uma construção curricular ou aplicação metodológica; uma proposta metodológica, que implica na utilização de uma obra artística (poema, pintura, letra de música, um filme) ou como instrumento para a discussão de algum conteúdo; e uma proposta curricular que descreve a organização de atividades escolares, estruturação e inclusão de conteúdos, por exemplo, sequências didáticas ou projetos escolares, em geral, processos mais longos e que incluem um trabalho interdisciplinar.

Quadro 1 - Compilação de trabalhos encontrados na literatura ${ }^{4}$

\begin{tabular}{|c|c|c|c|c|}
\hline Identificação & Área & Conteúdos & Relação com a temática & Abordagem \\
\hline $\begin{array}{l}\text { Reis; Guerra; } \\
\text { Braga (2006) }\end{array}$ & $\begin{array}{l}\text { Ciência da } \\
\text { Natureza }\end{array}$ & $\begin{array}{c}\text { Ciência numa } \\
\text { abordagem cultural. }\end{array}$ & $\begin{array}{c}\text { Ênfase para Física e } \\
\text { pintura. }\end{array}$ & $\begin{array}{l}\text { Discussão } \\
\text { teórica }\end{array}$ \\
\hline Zanetic (2006) & Física & $\begin{array}{l}\text { Aproximação da } \\
\text { Física com Arte e } \\
\text { História das Ciências. }\end{array}$ & $\begin{array}{l}\text { Literatura, letras de } \\
\text { música, aspectos } \\
\text { históricos e } \\
\text { epistemológicos. }\end{array}$ & Metodológica \\
\hline $\begin{array}{l}\text { Gorri e Santim } \\
\text { Filho (2009) }\end{array}$ & Química & $\begin{array}{c}\text { Abordagem química } \\
\text { para estudo } \\
\text { dos gases numa } \\
\text { perspectiva de } \\
\text { Filosofia, Sociologia } \\
\text { e História da Ciência } \\
\text { (FSHC). }\end{array}$ & $\begin{array}{c}\text { Aspectos históricos, } \\
\text { filosóficos e científicos do } \\
\text { quadro "Um experimento } \\
\text { com pássaro na bomba de } \\
\text { ar" de Joseph Wright. }\end{array}$ & $\begin{array}{l}\text { Proposta } \\
\text { curricular }\end{array}$ \\
\hline $\begin{array}{c}\text { Gomes; Di } \\
\text { Giorgi; Raboni } \\
\text { (2011) }\end{array}$ & Física & $\begin{array}{c}\text { Física numa } \\
\text { perspectiva FSHC }\end{array}$ & $\begin{array}{l}\text { Relações Física e pinturas } \\
\text { em diferentes épocas }\end{array}$ & $\begin{array}{l}\text { Proposta } \\
\text { curricular }\end{array}$ \\
\hline Ferreira (2012) & $\begin{array}{l}\text { Ciências da } \\
\text { Natureza }\end{array}$ & $\begin{array}{c}\text { Ciências/Física e } \\
\text { perspectiva cultural }\end{array}$ & $\begin{array}{c}\text { A Arte e Física (questões } \\
\text { metodológicas) }\end{array}$ & $\begin{array}{c}\text { Discussão } \\
\text { teórica }\end{array}$ \\
\hline Curcio (2013) & Física & Óptica & $\begin{array}{l}\text { Óptica e a Arte pictória, } \\
\text { Arte fotográfica, } \\
\text { cinematográfica e digital }\end{array}$ & $\begin{array}{l}\text { Discussão } \\
\text { teórica }\end{array}$ \\
\hline $\begin{array}{l}\text { Laburú; Nardi; } \\
\text { Zômpero } \\
\text { (2014) }\end{array}$ & Física & Energia mecânica & $\begin{array}{l}\text { A obra "Queda d'Água", } \\
\text { de Maurits Cornelis } \\
\text { Escher e conservação da } \\
\text { energia. }\end{array}$ & Metodológica \\
\hline $\begin{array}{c}\text { Oliveira; } \\
\text { Rodrigues; } \\
\text { Queiroz (2014) }\end{array}$ & $\begin{array}{l}\text { Ciências da } \\
\text { Natureza }\end{array}$ & $\begin{array}{c}\text { Relações entre } \\
\text { Ciência, Tecnologia e } \\
\text { Sociedade (CTS) }\end{array}$ & $\begin{array}{l}\text { Relação entre os poemas } \\
\text { de Fernando Pessoa e } \\
\text { discussão sobre CTS. }\end{array}$ & Metodológica \\
\hline $\begin{array}{l}\text { Velasquez } \\
\text { (2014) }\end{array}$ & Física & $\begin{array}{l}\text { Perspectiva de } \\
\text { cultura }\end{array}$ & $\begin{array}{l}\text { Concepções/ } \\
\text { representações do } \\
\text { conceito de cultura }\end{array}$ & $\begin{array}{l}\text { Discussão } \\
\text { teórica. }\end{array}$ \\
\hline
\end{tabular}

4 É importante destacar que a ausência de trabalhos que vinculam o Ensino de Biologia às Artes deve-se ao recorte que reduziu a quantidade de trabalhos, como a exclusão dos documentos referentes a anais de eventos. Além disso, a busca de informações livre na internet organiza os resultados da pesquisa de acordo com critérios de relevância variados, ressaltando algumas fontes em detrimento de outras. Somente uma busca minuciosa, que caracterize o estado de conhecimento da aproximação entre Artes e Ciência, pode revelar as relações com o Ensino de Biologia, Química e Física com confiabilidade. 


\begin{tabular}{|c|c|c|c|c|}
\hline $\begin{array}{c}\text { Lima e Ricardo } \\
\text { (2015) }\end{array}$ & Física & Variados & $\begin{array}{c}\text { Levantamento de } \\
\text { pesquisas entre Física e } \\
\text { Literatura. }\end{array}$ & $\begin{array}{c}\text { Discussão } \\
\text { teórica }\end{array}$ \\
\hline Ribeiro (2015) & Física & Óptica geométrica & $\begin{array}{c}\text { A arquitetura dos prédios } \\
\text { da Procuradoria Geral da } \\
\text { República e o ensino de } \\
\text { espelhos convexos. }\end{array}$ & $\begin{array}{c}\text { Proposta } \\
\text { curricular }\end{array}$ \\
\hline Silva (2015) & Física & Óptica geométrica. & $\begin{array}{c}\text { Óptica geométrica através } \\
\text { da aproximação da arte } \\
\text { urbana com a arte de } \\
\text { Joseph Wright. }\end{array}$ & $\begin{array}{c}\text { Proposta } \\
\text { curricular }\end{array}$ \\
\hline $\begin{array}{c}\text { Marques e } \\
\text { Razuck (2016) }\end{array}$ & $\begin{array}{c}\text { Ciências da } \\
\text { Natureza } \\
\text { (Química) }\end{array}$ & $\begin{array}{c}\text { Reações } \\
\text { fotoquímicas e } \\
\text { óptica }\end{array}$ & Fotografia. & $\begin{array}{c}\text { Proposta } \\
\text { curricular }\end{array}$ \\
\hline $\begin{array}{c}\text { Ducheiko e } \\
\text { Silva (2017) }\end{array}$ & Física & Astronomia & $\begin{array}{c}\text { Astronomia a partir da } \\
\text { cultura indígena }\end{array}$ & $\begin{array}{c}\text { Proposta } \\
\text { curricular }\end{array}$ \\
\hline $\begin{array}{c}\text { Fernandes et } \\
\text { al. (2017) }\end{array}$ & Física & Física moderna & Mecânica quântica. & $\begin{array}{c}\text { Proposta } \\
\text { curricular }\end{array}$ \\
\hline
\end{tabular}

Fonte: As autoras.

Além de propiciar aprofundamentos referentes às articulações ciência, cultura e arte, a análise permitiu sinalizar referenciais, proposições, recursos, conhecimentos científicos e aspectos socioculturais que podem auxiliar na construção de um projeto curricular. Dessa forma, no terceiro momento apresentamos essas sistematizações.

Fundamentado pelas teorias críticas e pós-críticas de currículo (SILVA, 2014), de constituição identitária (ARROYO, 2013) e pelos pressupostos da abordagem temática (DELIZOICOV; ANGOTTI; PERNAMBUCO, 2011), o tema Ciência e Cultura: a Arte nas mais diversas representações emergiu do potencial em dar visibilidade para o Ensino de Ciências em uma perspectiva sociocultural, marcada pelo entendimento de ciência como construção humana e cultural. Embora o tema não tenha passado por um processo investigativo no ambiente escolar, de uma demanda localmente vivenciada ele pode ser considerado relevante, pois permite problematizar a racionalidade hegemônica da ciência, fundamentada pela descontextualização, fragmentação e hierarquização de saberes. Ou seja, dá visibilidade para aspectos, em geral, silenciados na área, como a diversidade identitária, cultural e os saberes produzidos nesses contextos, portanto olhares contra-hegemônicos. Complementar ao exposto, apresentamos uma dinamização curricular fundamentada pelos Três Atos do Teatro (Espaço Físico, Voz e Corpo). A linguagem teatral, marcada pela autonomia, criatividade e ludicidade, possui papel importante no processo de aprendizagem dos artistas. Dessa maneira, por que não a utilizar como estratégia para repensar o Ensino de Ciências? Assim, apresentamos, também, uma proposição centrada nesse recurso.

\section{CURRÍCULO: Teorias e Implicações Para o Ensino de Ciências}

Os entendimentos que surgem ao interpretar o currículo escolar, suas finalidades e concretização, geram corpos de conhecimento e de análise que se dividem em teorias de currículo. No que diz respeito às teorias críticas, Silva $(2014$, p. 46) destaca a perspectiva de Michael Apple, em que "o currículo não é um corpo neutro, inocente e desinteressado de conhecimentos". Ele reflete a hegemonia de uma classe que se con- 
cretiza não apenas pela dominação econômica, mas também no campo social/cultural. Para Apple (apud SILVA, 2014), o currículo escolar consiste em um dos mecanismos de manutenção da dominação, pois "a seleção que constitui o currículo é o resultado de um processo que reflete os interesses particulares das classes e grupos dominantes" ( $p$. 46). Ainda, sua efetivação implica que "A distribuição do conhecimento está socialmente segura enquanto ela for aceita de um modo geral ou pelo menos não for questionada eficazmente, por mais desigual que ela possa ser" (HAFT; HOPMANN, 1990, p. 159 apud GOODSON, 2013b, p. 29).

A partir desta análise é válido problematizar o fato de que se as teorias de currículo anteriores se limitaram a responder como o currículo deve ser organizado, preocupado principalmente com questões técnicas, a teoria crítica atenta-se em responder o porquê, pois esta pergunta revelará para qual finalidade social a escola e seu currículo estão direcionados. Assim, quando um mesmo currículo é disseminado, o que parece coerente com o pensamento de acesso a todos à mesma educação, ele pode ser instrumento de exclusão, pois determina o que deve ser trabalhado em sala de aula, “[...] até mesmo às crianças que frequentavam a mesma escola podiam ter acesso ao que representava 'mundos' diferentes através do currículo a elas destinados" (GOODSON, 2013a, p. 33, grifo do autor).

Além do exposto, Apple (apud SILVA, 2014) problematiza que, mesmo quando o currículo é reflexo da reprodução social, este processo não é feito sem que haja contra-hegemonia, ou seja:

As pessoas precisam ser convencidas da desejabilidade e legitimidade dos arranjos sociais existentes. Mas esse convencimento não se dá sem oposição, conflito e resistência. É precisamente esse caráter conflagrado que caracteriza um campo cultural como o do currículo. Como uma luta em torno de valores, significados e propósitos sociais, o campo social e cultural é feito não apenas de imposição e domínio, mas também de resistência e oposição (SILVA, 2014, p. 49).

Nas teorias pós-críticas estas reflexões ampliam-se. O pós não implica superação/ substituição das teorias críticas, mas acrescenta o fato de que as relações de poder não se reduzem às estruturas econômicas e de classe; elas estendem-se às relações de gênero, etnia, raça e sexualidade. O poder é multifacetado, está em toda parte, se apresentando ora de forma explícita ora de forma silenciosa, e o currículo escolar corporifica esta realidade; ele é "uma questão de saber, identidade e poder" (SILVA, 2014, p.147). A dinâmica social que influencia a escola, as identidades de professores e estudantes, é permeada pela presença de movimentos sociais (feminista, LGBT, movimento negro, indígena, quilombola, do campo, etc.) que pressionam por currículos que tratem dessas identidades coletivas, ações afirmativas e inclusivas, e isso requer novos perfis de docência, maior riqueza de profissionais e disputas pelo currículo (ARROYO, 2013).

A partir destes debates não é possível ser alheio às propostas curriculares. $O$ currículo reproduz as relações sociais de poder e se constitui em aparelho ideológico e em um território político de disputa (SILVA, 2014). Nesse ínterim, "As lutas históricas no campo do conhecimento foram e continuam sendo lutas por dessacralizar verdades, dogmas, rituais, catedráticos e cátedras. A dúvida fez avançar as ciências e converteu o conhecimento em um território de disputas" (ARROYO, 2013, p. 17). Percebe-se, então, 
que o currículo é um conceito multifacetado, construído, negociado e renegociado em vários níveis e campos. Surgem conceitos filosóficos, psicológicos, sociológicos, assim como perspectivas mais técnicas, racionais ou científicas, que recebem críticas duras. Afinal, o currículo não pode ser resumido à prescrição, mas como construção social em nível de processo e prática (GOODSON, 2013a), que constrói o tipo de ser humano desejável para um tipo de sociedade, constituindo-se "[...] tanto a uma questão de conhecimento quanto a uma questão de identidade" (MOREIRA; TADEU, 2018, p. 7).

Assumindo o viés identitário do currículo, é importante reafirmar os estudantes como sujeitos da sua aprendizagem e a escola como acolhedora das diversidades que os compõem, pois não basta incluir os estudantes numa estrutura escolar tradicionalista, excludente e segregadora; haverá confrontos, e estes são utilizados, geralmente, para negativar a atuação dos jovens, como responsabilizá-los pelos fracassos de seus resultados, como expõe Arroyo (2013). Logo, segundo este autor, é importante incorporar as desordens sociais que

(...) esses jovens e adolescentes padecem, vivem e carregam às escolas porque se ignora a desordem social nos conhecimentos curriculares, nas disciplinas e avaliações. As visões épicas, progressistas que predominam nos conhecimentos disciplinares ocultam o real trágico da história e da desordem social. Quando chegam as vítimas dessas tragédias sociais às escolas ficamos confusos sem referências conceituais para entendê-las (p. 240).

É necessário, para reconhecer estas desordens, enxergar os educandos como sujeitos ativos-afirmativos (lembrando que a forma como os reconhecemos nem sempre são a forma que eles se reconhecem): Quem são? O que sentem? Aspiram? Lutam? Como vivem? Em que família? Como vivenciam a escola? Os amigos? O estudo? As avaliações? As disciplinas? O abandono? As marcas positivas/negativas dos mestres? Isso posto dentre outras dimensões de suas vivências, pois:

Cada uma delas abre espaços para o que é a função precípua da escola e do currículo: garantir o conhecimento de si mesmos, das formas de seu viver, dos direitos garantidos ou negados, as causas e determinações sociais, econômicas, políticas que precarizam ou permitem suas formas de viver, sobreviver. Seriam esses os conhecimentos primeiros a que têm direitos? (ARROYO, 2013, p. 254).

O currículo, portanto, é um território de disputa, e a manutenção de formatos, o engessamento, o peso normatizante que ele possui, não é aleatório, e se o Ensino de Ciências de hoje é semelhante ao do século passado: Quais formas de currículo disputaremos? Que formação/identidade de sujeitos constituiremos? Dessa maneira, que indicativos e proposições no âmbito de pesquisas da área temos para pensar outros direcionamentos?

Nesse sentido, evidenciamos a potencialidade da abordagem temática para um repensar curricular no Ensino de Ciências. A abordagem conceitual e a temática representam perspectivas, objetivos e orientações educacionais diferentes. Enquanto a primeira baseia-se na lógica disciplinar e de reprodução do conhecimento, a abordagem temática aproxima-se da realidade dos sujeitos que vivenciam a escola, possibilitando desvelamento de contradições sociais (DELIZOICOV; ANGOTTI; PERNAMBUCO, 2011). Dessa maneira, ela emerge como possibilidade para superar a concepção tradicional de 
currículo, pois questiona as intencionalidades por trás da sua proposição. Há, portanto, um distanciamento de questões meramente técnicas para uma aproximação/preocupação do "o que ensinar" e "por que" ensinar (SILVA, 2014).

Strieder et al. (2011), em uma investigação sobre a abordagem de temas na pesquisa em Educação em Ciências, destacam que, embora a proposição da abordagem temática, proposto por Delizoicov, Angotti e Pernambuco (2011), tenha sua gênese nos pressupostos de Paulo Freire, para os autores "ela não se reduz a este referencial, podendo ser explorada com base em outros pressupostos educacionais" (p. 2). Assim, da investigação realizada por Strieder et al. (2011) há diferentes perspectivas centradas na proposição de temas, como os pautados pelo enfoque ciência-tecnologia-sociedade em temas ambientais, nas situações de estudo, temas freirianos, unidades de aprendizagem e temas conceituais e contextuais. Embora cada proposição tenha suas especificidades, as autoras destacam que as propostas se aproximam em razão das preocupações com atribuição de significados para o conteúdo escolar, em especial a partir da contextualização e da interdisciplinaridade. Assim, independente da perspectiva adotada para repensar configurações curriculares no âmbito do Ensino de Ciências, a abordagem temática tem seu eixo central na estruturação de programas para auxiliar os professores a selecionar quais conhecimentos científicos precisam ser abordados no processo educativo. O objetivo, portanto, está na articulação dos conhecimentos científicos aos temas que serão problematizados/trabalhados, pois são os temas, e não os conceitos científicos, o ponto de partida para a elaboração do programa, "que deve garantir a inclusão da conceituação a que se quer chegar para a compreensão científica dos temas pelos alunos" (DELIZOICOV; ANGOTTI; PERNAMBUCO, 2011, p. 273).

Deste modo, considerado elemento essencial na estruturação da abordagem temática, a interdisciplinaridade é um desafio tanto teórico quanto prático a ser enfrentado. Isso porque definir a interdisciplinaridade não é uma tarefa fácil. Em geral, é entendida como o que há de comum entre as ciências; no entanto, para Fazenda (2012), "[...] uma atitude interdisciplinar se identifica pela ousadia da busca, da pesquisa, da transformação [...]" (p. 88), ampliando o seu sentido a uma atitude, uma maneira de se relacionar com o conhecimento, como parte das identidades pessoal e coletiva em determinado contexto histórico-social. Na leitura de Mozena e Ostermann (2017) sobre esta autora, a interdisciplinaridade

[...] deve ser relacionada aos sujeitos, suas interações sociais e sua vida, pois só se legitima na ação. Sendo assim, portanto, a teoria interdisciplinar é um fazer social, permeado de atitudes. Também "[...] precisa ficar claro que em termos de conhecimento estamos ainda em fase de transição" (FAZENDA, 2013, p. 16) e que a "interdisciplinaridade é essencialmente um processo que precisa ser vivido e exercido" (FAZENDA, 2001, p. 11 apud MOZENA; OSTERMANN, 2017).

Para Fazenda (2011), a interdisciplinaridade não nega a disciplinaridade, assim como "[...] há a necessidade de se desenvolver tanto a competência disciplinar, como a interdisciplinar" (apud MOZENA; OSTERMANN, 2017, p. 101). Dessa forma, mesmo compreendendo que cada campo de saber possui especificidades, as relações individuais e coletivas de sujeitos e áreas possibilitam riqueza de olhares sobre o mundo, aspecto essencial no âmbito da abordagem temática. Ademais, a interdisciplinaridade 
é um desafio, pois implica diversos fatores de trabalho: parceria entre os envolvidos; o perfil de uma sala de aula interdisciplinar que envolve espaço, tempo, disciplina e avaliação diferenciados do tradicional; e um projeto interdisciplinar, coerente, objetivo, detalhado, posto que a interdisciplinaridade não é realizada com improvisação e acomodação (FAZENDA, 2012), tampouco "se configura num vale tudo" (MOZENA; OSTERMANN, 2017, p. 97).

Ao considerar esta perspectiva de interdisciplinaridade, acredita-se que é possível um alinhamento com Arroyo (2013), para o qual o currículo marca as identidades, e com Goodson (2013b), em que uma mudança de currículo se opera por meio de processos internos (ambiente escolar), externos (fora da escola) e pessoal (crenças e missões pessoais). Ao considerar-se as realidades e histórias de vida dos sujeitos (MOZENA; OSTERMANN, 2017), há a aproximação com o enfrentamento de situações-problema que surgem na comunidade escolar (LISBOA; BEJARANO, 2013) em consonância com a abordagem temática, em que a interdisciplinaridade é entendida como olhar coletivo entre os campos do saber para a compreensão e enfrentamento de um tema/problema (FERREIRA; MUENCHEN; AULER, 2019).

\section{DIÁLOGOS ENTRE CIÊNCIA, CULTURA E ARTE}

Quando falamos em cultura, ou em arte nas suas diversas representações socioculturais em geral, a área de Ciências da Natureza pouco comparece e é elucidada. Reconhecer a ciência enquanto cultura, no entanto, é uma demanda necessária, pois "a ciência se desnuda para nós como parte da cultura e pode nos ajudar a compreender melhor o processo histórico que nos trouxe até aqui" (REIS; GUERRA; BRAGA, 2006, p. 71). Além disso, arte e ciência são atividades socialmente construídas, embasadas pela criatividade e curiosidade; logo estão entrelaçadas pela cultura humana.

Dessa maneira, os imbricamentos presentes entre ciência, cultura e arte têm sido foco de discussão de diferentes pesquisadores da área de Educação em Ciências (ZANETIC, 2006; REIS; GUERRA; BRAGA, 2006; VELASQUEZ, 2014). Esses estudiosos têm apontado possibilidades e caminhos para a inserção de propostas educativas para o âmbito escolar. Assim, considerando que o nosso intuito está em repensar configurações curriculares, tendo como ênfase as articulações ciência, cultura e arte, como os trabalhos publicados na área podem contribuir para essa proposição? Que indicativos presentes neles evidenciam potencialidades e limitações tendo em vista os estudos anteriormente apresentados?

Nesse sentido, Azevedo, Barbosa-Lima e Queiroz (2007) alegam, por exemplo, o fato de a articulação ciências e artes possibilitar dinamizar as aulas, aguçar a curiosidade e mostrar que as Ciências da Natureza não são frias e impessoais, rompendo com a dicotomia razão e sensibilidade, que alimenta os estereótipos do cientista gênio frio $e$ isolado e do artista puro sentimento, mas mostra que ambos os sujeitos misturam razão e sensibilidade nas suas formas de ver o mundo. Além disso, as articulações presentes entre ciência, cultura e arte permitem discutir o papel do conhecimento científico e tecnológico numa perspectiva sociocultural e histórica, o que nos remete aos debates do que é ciência e tecnologia, seus direcionamentos e contribuições, seus impactos (para a humanidade e para a natureza), a ética e a moral associada à construção do conheci- 
mento. A contextualização histórica, todavia, não deve ser linear, estabelecida, simplesmente, em datas, marcos e nomes, mas demonstrar como ela é uma construção social, reflexo da sociedade, de suas disputas, lutas e contradições em determinada época e local. Desse modo, ao aproximar a ciência da arte, dialogando com (e como) culturas, este cenário torna-se um caminho possível.

Tanto a arte quanto a ciência expressam noções da realidade e da natureza, e, por meio de linguagens próprias, constroem representações e difundem práticas. Ambas são campos resultantes da cultura; constroem-se e se reconstroem, variando de uma sociedade para outra. A arte deve ser histórica e realizada numa perspectiva social que envolve

[...] a observação, a análise da relação entre o artista e o seu contexto para responder como um conteúdo de experiência se transmuta em uma linguagem formal. Em outras palavras, "[...] $\mathrm{O}$ artista pode até perceber como única a experiência para qual encontra uma forma, mas a história da cultura demonstra que se trata de uma resposta social a mudanças objetivas [...]" (CEVASCO, p. 153 apud ALAMBERT, 2014, p. 14).

É necessário salientar que o objetivo não é definir a arte, afinal na área não há consenso sobre o que ela é (COLI, 1995). A arte é cultura, é campo de disputa, reflete a sociedade e seu tempo, assim como a ciência, e neste sentido ambos os campos convergem. Por exemplo, o Renascimento é um movimento importante da nossa história e que muito contribuiu para a forma como a humanidade pensa arte e ciência. Nele, encontra-se o exemplo da não separação entre estes campos, como em Leonardo Da Vinci, na materialização do ideal do homem renascentista, de personalidade multifacetada e multiplicidade de interesses, para citar pintura, arquitetura, escultura, anatomia, física e astronomia. Cada produção nestes campos articula-se com os demais; por exemplo, seus estudos de anatomia refletem o domínio do desenho na experimentação e vice-versa, o Homem de Vitrúvio e a matemática das proporções perfeitas (CACHAPUZ, 2014).

Antes do Renascimento, o mundo (basicamente, na Europa Ocidental) era visto a partir da cosmologia medieval-aristotélica, na qual o universo era dividido em dois mundos diferentes (sublunar e supralunar). As pinturas refletiam essa dualidade ao representar paisagens em que o céu (sagrado) não possuía continuidade com a terra (mundano); diferente da pintura renascentista, cujo uso da perspectiva e do claro-escuro possibilitou uma nova concepção espacial de infinitude numa representação de mundo agora não mais repartido. Estas duas técnicas influenciaram as observações empíricas e os seus registros (REIS; GUERRA; BRAGA, 2006). Os autores, nesse sentido, ressaltam:

Os desenhos que Galileu fez da Lua como havia visto com suas lunetas são emblemáticos. Foi o conhecimento de desenho, do claro-escuro, adquirido por Galileu em Florença que Ihe possibilitou compreender a aparência da Lua. A geometrização da projeção das sombras pode ter Ihe permitido perceber as irregularidades da superfície lunar. Ele foi capaz, até mesmo, de determinar a altura das montanhas lunares, novamente valendo-se da perspectiva. Assim, a Lua representada por 
Galileu deixou de ser a imagem da perfeição - associada, no imaginário cristão, à Imaculada Conceição - e passou a ser mais um corpo celeste com características comuns, como a Terra (p. 72).

As relações entre estes dois campos resultam numa prática interessante para a área de Filosofia, Sociologia e História da Ciência (FSHC). Por exemplo, Alcantara e Braga (2017) desenvolveram uma proposta para o ensino de óptica articulado às redes de relações sociais de Constantijn Huygens na Holanda do século 17, relacionando aspectos sociais, econômicos, artísticos, filosóficos e científicos da época, afinal, "Nesse momento, a fabricação de lentes era uma das atividades econômicas de grande importância na Holanda. Vários cientistas, filósofos e artistas da época trabalharam como polidores de lentes" (p. 119). Este contexto refletiu-se numa pintura de descrição da realidade que incorporou instrumentos ópticos, como a câmara escura, nos ateliês de pintura.

Os quadros do barroco holandês são vistos como obras de artes altamente realistas. A Vista de Delft, de Johannes Vermeer, por exemplo, é considerada um dos quadros mais próximos de uma fotografia. Ou, ainda, "A Leiteira" (Figura 1), deste mesmo artista, cuja sensação de movimento/vivacidade está presente, como um vídeo pausado que a qualquer momento voltará a se movimentar.

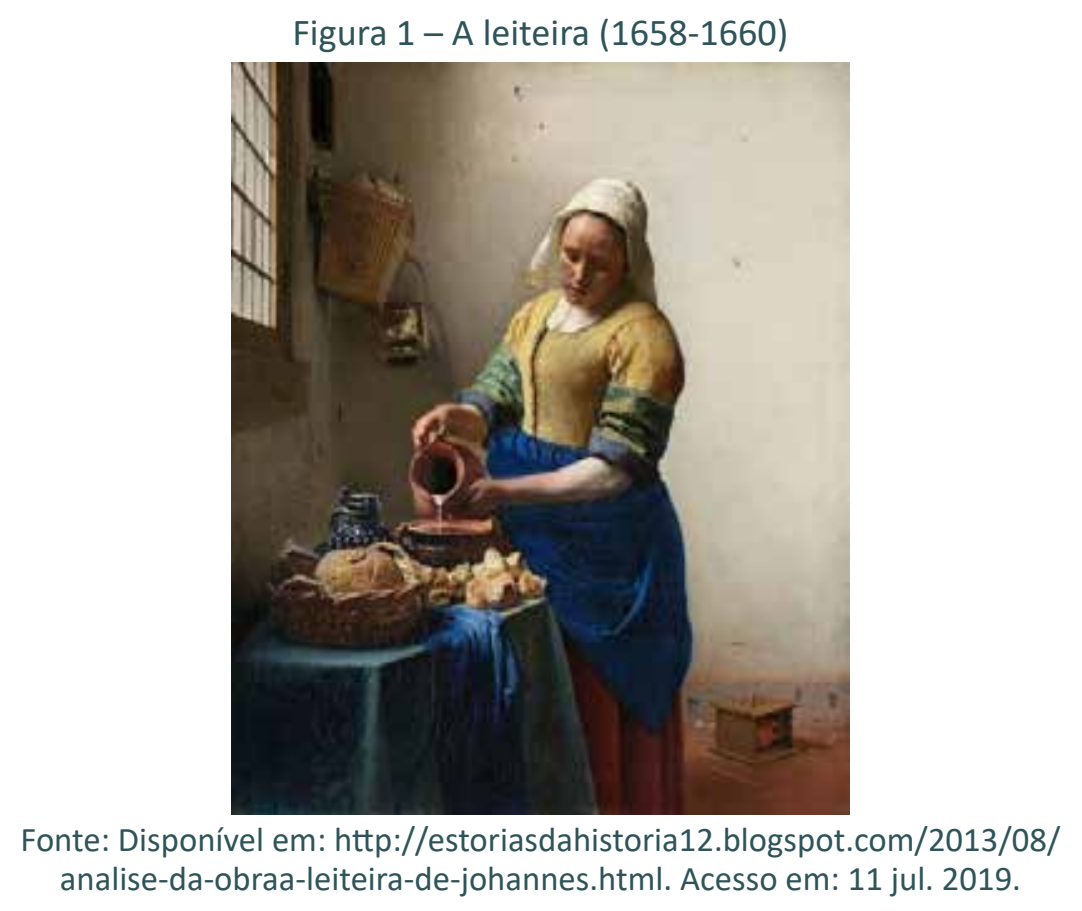

No quadro apresentado na Figura 1, a cesta em primeiro plano está fora de foco comparada à cesta do fundo, algo que não é possível de perceber a olho nu, pois nossos olhos tendem a regular o foco quando alternamos o objeto principal da visão (ALCANTARA; BRAGA, 2017). O diálogo ciência e arte poderia ser provocado para trabalhar conceitos ópticos como a propagação retilínea da luz em relação à fonte (janela), problematizando, por exemplo: Qual o tipo de fonte de luz? Há formação de sombras? Há algum equívoco no quadro? Esta última muito importante, pois o canto direito do alto aparece como uma fonte de iluminação que não é originária da janela, ou seja, estaria errônea dentro do entendimento da propagação retilínea da luz; no entanto este é um efeito 
comum em obras barrocas, de luzes "sobrenaturais"; em outras palavras, há liberdades artísticas em desacordo com o científico. Efeitos como este são encontrados em outras obras do Johannes Vermeer, como em a "Moça com brinco de pérola" (Figura 2), na qual supostamente foi utilizada uma câmara escura de orifício, de modo que o fundo escuro dá ênfase à tridimensionalidade da projeção da moça, gerando maior realismo, fazendo-nos perguntar se ela está olhando para nós quando chamada ou desviando o olhar de nós.

Figura 2 - Moça com brinco de pérola (1665-1666)

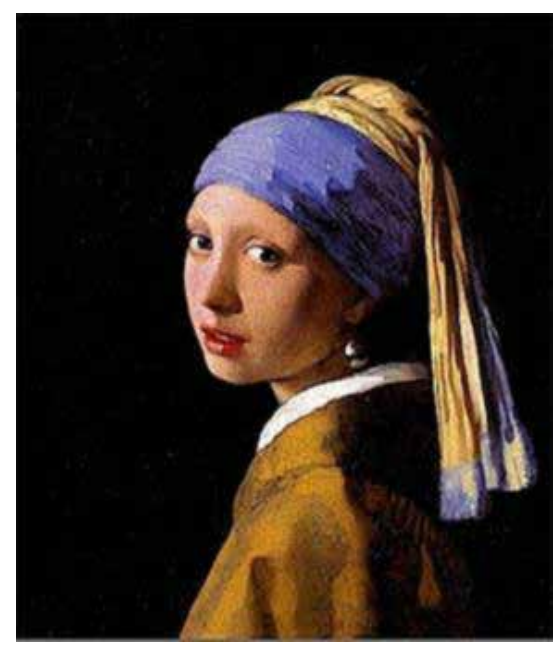

Fonte: Disponível em: https://arteeartistas.com.br/moca-com-brinco-de-perola-johannes-vermeer/. Acesso em: 11 jul. 2019.

Repensar o currículo a partir do uso desta articulação não se restringe apenas à inserção de uma perspectiva de FSHC, mas tem potencial para discutir, significativamente, conceitos, processos e práticas de investigação. Além disso, trabalhar com artes e suas diferentes representações socioculturais não se limita a uma perspectiva elitista dos discursos que determinam o estatuto da arte e o valor de um objeto artístico, afinal estes variam no tempo e em diferentes sociedades (COLI, 1995), criando hierarquias que silenciam certas manifestações artísticas.

Nesse sentido, Silva (2015), baseando-se na relação arte e ciência, desenvolveu uma transposição de conceitos da óptica geométrica a partir do tema arte urbana (grafite), como ligação para o uso da arte de Joseph Wright a partir da tela "An Experiment on a Bird in the Air Pump", de 1766. Este artista foi escolhido pelos temas presentes em suas obras, pois muitas delas retratam cenas que remetem à prática científica e são ricas em representação dos efeitos luminosos (sombras, reflexos, penumbra e refração) com clareza e precisão. Para a autora, o grafite era um elemento significativo/representativo da realidade dos seus estudantes, uma representação artística organizada de maneira diferenciada das obras que fazem parte dos períodos clássicos da história da arte. Junto a isso, está exposta de forma integrada ao ambiente urbano, em seus muros e construções, com múltiplas mensagens (da legalização à violência policial) e técnicas, que nem sempre apresenta autoria. Ou seja, é um exercício que representa "[...] diversão, espaço de sociabilidade e lugar da resistência, da denúncia, do protesto e da manifestação da busca por significados de vida" (PROSSER, 2009 apud SILVA, 2015). 
Complementar ao exposto, há também o trabalho de Ducheiko e Silva (2017), que apresenta uma proposta interdisciplinar que une a arte e a ciência das culturas indígenas $^{5}$ para o ensino de astronomia. Na primeira parte do texto, os autores fazem uma revisão bibliográfica sobre as culturas indígenas, suas artes visuais e sua astronomia. Nesse sentido, relacionam estas esferas com questões organizativas da comunidade (tempo de colheita, pescas, rituais) à produção de diversos objetos, como o Mekutom, um ornamento masculino usado em ciclo cerimonial pelos Caiapós. Esse objeto demonstra a integralidade da arte desse povo com seus saberes astronômicos, uma vez que visualmente descreve o Universo Caiapó em termos de espaço e tempo. Na segunda parte, os autores apresentam uma proposta resultante de uma transposição didática em razão da complexidade dos saberes indígenas, "para não formar nos alunos uma visão estereotipada e descontextualizada do tema" (p. 278).

Por fim, destacamos que as aproximações entre ciência, cultura e artes, nas suas mais diversas representações, pode ser um caminho para discutir aspectos socioculturais vividos, hegemônicos e contra-hegemônicos. É, no entanto, a partir de temas de contradições sociais, de aproximação com a realidade dos sujeitos que vivem o currículo, que os propósitos das teorias crítica e pós-crítica se potencializam. Além disso, serão esses temas que permitiram incorporar demandas identitárias múltiplas, em geral silenciadas no ensino de Ciências da Natureza.

\section{CONFIGURAÇÕES CURRICULARES PARA O ENSINO DE CIÊNCIAS}

Ferreira (2012), em uma análise sobre a arte no Ensino de Ciências, evidenciou a ênfase, principalmente, para uma abordagem metodológica, pois “[...] suas potencialidades são percebidas mais como instrumentos para o ensino do que como ativa participante na construção de relações acerca da natureza e do próprio homem" (p. 1). Dentre os motivos apresentados pelo autor, está a dificuldade de propiciar essas relações, tendo em vista que "[...] não é tarefa fácil, pois implica o conhecimento de ambas as áreas para que se percebam os contatos" (p. 5); desafio este que se liga à interdisciplinaridade e, também, ao pensar/fazer currículo nessa perspectiva.

Usar a arte como estratégia metodológica é significativo, mas a construção de currículo é mais relevante quando se pensa em propostas e objetivos mais amplos e que permitem abandonar o tradicional; ela é submetida a uma linearidade e conformação de conteúdos disciplinares. Como proposição curricular existe um potencial de possibilitar problematizações que podem ser exploradas pela dimensão investigativa da ciência, além de viabilizar diálogos abrangentes entre culturas, momentos históricos, influências e contradições sociais e econômicas vividos.

Assim, motivados por essas intencionalidades e pelos referenciais assumidos neste trabalho, propomos o tema Ciência e Cultura: a Arte nas mais diversas representações. Esse tema permite olhar para a ciência e apreendê-la como um produto histórico, pois essa não é uma relação causal, mas significativa do próprio processo de construção de conhecimento. Nesse sentido, é possível alcançar uma formação humana na qual

No plural, uma vez que no Brasil existem muitas etnias, cada qual com seus valores, costumes e saberes (DUCHEIKO; SILVA, 2017). 
os conceitos geram novos olhares para a realidade, e a realidade faz o mesmo com os conceitos, assim como novas atitudes perante o conhecimento podem ser construídas e novas leituras sobre a realidade vivida podem ser proporcionadas. A arte, nas suas mais diversas representações no âmbito escolar, tem potencial de oferecer aos sujeitos uma formação estética e um desenvolvimento cultural e identitário, possibilitando a construção de conhecimentos por intermédio das diversas linguagens que se articulam com a verbal, por meios de expressões e comunicações que a arte propicia em larga escala. Aspectos que possibilitam desenvolver nos estudantes um olhar sensível, crítico, lúdico e espontâneo, e ampliam os horizontes para a coletividade. Pensar o currículo a partir da temática apresentada rompe-se com abordagens tradicionais, oferecendo uma multiplicidade de conhecimentos aos estudantes, conhecedores de saberes afetivo e emocional, proporcionando compreender as questões sociais e culturais, sejam elas passadas/futuras, gerando um pensamento crítico-reflexivo.

Em termos de conteúdo, o tema permite dialogar com diferentes áreas do saber. Referente às Ciências da Natureza, destaca-se: ondas sonoras dos instrumentos musicais e dos timbres de cada voz; da óptica das fotografias e do cinema; da refração da luz em vitrais; iluminação, som e efeitos naturais utilizados no teatro e cinema; até mesmo pela mecânica newtoniana da arquitetura de prédios, e de cada movimento corporal da dança ou da arte circense, e aí já discutir o metabolismo energético; os materiais utilizados nas artes, assim como suas transformações (como a areia se converte a vidro?) e as funções orgânicas dos pigmentos e sua extração de fontes naturais para obtenção de tintas; a literatura de ficção científica; a natureza como fonte de materiais e de inspirações; etc. Além dos conceitos, a temática traz consigo problematizações variadas, por exemplo, obras de artes como crítica social, podendo ser usadas como ponto de partida para discutir questões como relatividade e radioatividade; a toxicidade dos materiais; o desempenho dos artistas associado ao aspecto físico; a utilização das ciências física e química na validação e conservação de obras de artes; a problemática das construções ilegais; arte e saúde, sua utilização no tratamento de doenças; educação ambiental, etc. Ademais do exposto, é possível discutir a história da arte, a literatura, a geometria, a educação física e o corpo, os direitos humanos, as culturas, etc. A arte nas suas mais diversas representações é, portanto, um caminho, uma fonte rica e ampla para motivar a estruturação de currículo.

Com base, portanto, no levantado (Quadro 1) e em estudos realizados, apresentamos uma configuração curricular com possíveis articulações para diferentes conteúdos. Na Figura 3 o tema geral Ciência e Cultura: a Arte nas mais diversas representações (vermelho) permite articulações com diversos subtemas, ou manifestações de artes (roxo), fotografia, teatro, arquitetura, etc., com conteúdos de ciências (laranja), com todas estas relações imersas no âmbito da cultura e sociedade (verde), permitindo a discussão com temas de relevância social, identitária e de aspectos contra-hegemônicos. Destacamos que a configuração apresentada constitui uma dentre diversas possibilidades possíveis. 


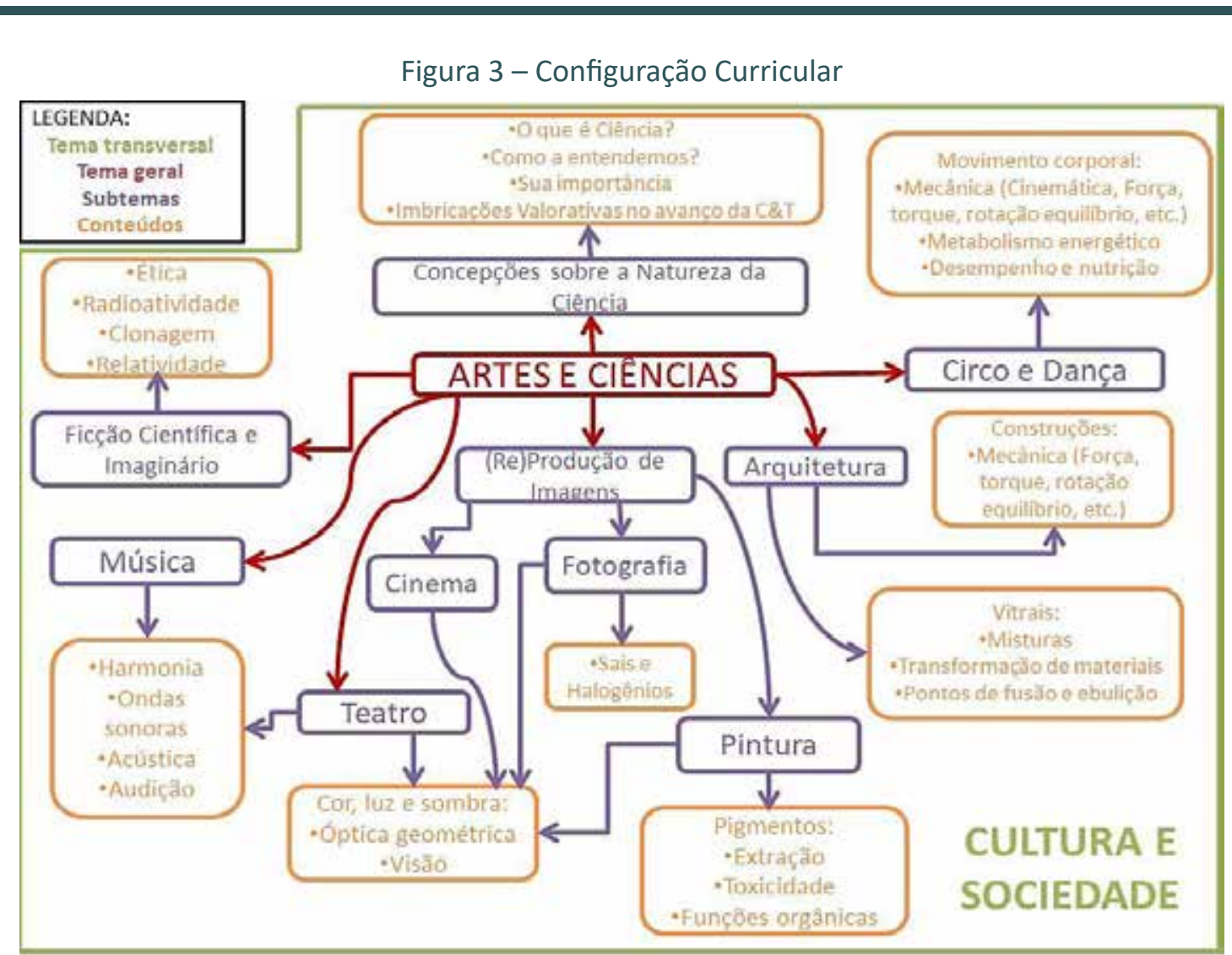

Fonte: As autoras.

Além do exposto, apresentamos outro encaminhamento dividido nos três Atos do Teatro: espaço físico, voz e corpo. A escolha pelos Atos se dá pela importância que eles possuem no âmbito teatral, musical e no cinema. A linguagem artística, imbricada pelo desenvolvimento corporal, físico, de comunicação e de interação, tem potencial de promover a criatividade e a ludicidade, logo contribui para a constituição de protagonismos. Os Atos e suas imbricações com a Ciência, Cultura e Arte, todavia, sinalizam outro caminho para repensar o currículo. Assim, apresentamos, a seguir, possíveis delineamentos.

10 Ato - Espaço Físico: a arte de interpretar reúne vários elementos que podem ser explorados nas aulas, uma delas é a estética do espetáculo, pois apenas o texto (supremo no século 19) é insuficiente para a interpretação que o espectador faz da cena. Tudo que existe e é visível ou não visível no palco é passível de leitura pelo espectador, seja ela por via racional/cultural ou via sensorial/empírica, como os elementos em cima de um palco e os signos que eles representam. Por exemplo, as cores e as emoções associadas a cada uma delas, assim como a mistura entre elas, que gera efeitos ópticos. As cartelas usadas em um espetáculo teatral implicam discussão sobre cores, luz e sombra para compor melhor o cenário, luz e figurino (cuja escolha de cores produz contrastes e efeitos propositais de movimento). Nesse sentido, a estética de um espetáculo pode ser trabalhada em sala de aula para que os estudantes possam estudar as dimensões das cores, o tom, o valor, a saturação, a tonalidade e os contrastes. Logo, aprendizagens de colorimetria de uma forma lúdica, cultural e de multiconhecimento. 
20 Ato - Voz: na cena, a voz torna-se chave importante dentro do processo da expressão cênica, ao mesmo tempo em que se torna abstrata, pelo fato de ocupar um espaço não perceptível aos olhos. A voz propaga-se por meio das ondas sonoras, em meios materiais, pelo ar, sofrendo diferentes reflexões que vão depender das interferências ambientais. Os humanos têm a capacidade de vocalizar sons, e estes consistem no sistema de variações que é sincronizado com o ouvinte, e a cada mudança de ritmo respiratório percebe-se uma nota dissonante na fala. Assim, pode-se trabalhar as técnicas de aquecimento vocal para que essa capacidade de vocalizar sons possa ser estudada. Complementando, pode ser trabalhada também a audição humana, suas características, constituição, intensidade, abordando desde conceitos voltados para a biofísica (composição auditiva) até os fenômenos físicos do som e a sua propagação até atingir o aparelho auditivo.

30 Ato - Corpo: a preparação corporal é algo importantíssimo; é material de trabalho para o ator, é caminho de expressão. Por exemplo, a mímica corporal dramática, para Etienne Decroux (ator e mímico francês), é o instrumento de quando se desprende de todos os manifestos vocais. Para ele, a sua importância é tanta que "[...] quando o corpo se levanta é toda a humanidade que se levanta" (DECROUX apud LEABHART, 1978 , p. 63). Para o ator, a presença corporal em cena diz muito e a ciência pode dar um novo olhar para a realização dos exercícios e para os movimentos na mímica e na preparação corporal do artista; não somente do ator tradicional, mas também os de musical e dançarinos e a compreensão dos seus movimentos, como piruetas em cena. Além desses, há também o artista circense, suas manobras de malabarismo, de acrobacias, quando cada ato corporal, cada coreografia, é calculada e estudada para que as forças externas que envolvem cada ato sejam previsíveis.

Em geral, os olhares para os conhecimentos na sistematização das proposições tiveram sua ênfase para a área de Física, no entanto isso não se deu de maneira aleatória, mas em razão da área de formação das autoras. Defende-se uma construção interdisciplinar, porém a sua efetivação se potencializará com o engajamento de um coletivo, pois, conforme apontado por Fazenda (2012), a interdisciplinaridade é uma atitude coletiva e intencional alicerçada no diálogo e na colaboração entre professores da mesma área e áreas distintas. As configurações realizadas, no entanto, permitem vislumbrar possibilidades de ensino interdisciplinar para a área de Ciências da Natureza.

\section{CONSIDERAÇÕES FINAIS}

Uma discussão muito presente quando a ênfase é currículo é saber o que ensinar, ou seja, por que escolher um conhecimento em detrimento de outro? O que garante que um é mais importante que outro? (SILVA, 2014). Essas problematizações, marcantes nas teorias críticas e pós-críticas de currículo, contribuem para análises crítico-reflexivas sobre o pensar/fazer currículo. Nesse sentido, no Ensino de Ciências a abordagem temática tem sido considerada um caminho sinalizador ante a esses desafios. Fundamentada por uma estrutura com base em temas e não em conceitos, a abordagem temática auxilia na definição de conhecimentos, de demandas da sociedade e de interesses dos estudantes que podem ser inseridos no processo educativo. Nessa proposição, a realidade do estudante representa o ponto de partida e também o de chegada. O novo olhar 
para as situações trabalhadas, no entanto, não é o mesmo, mas é coberto de ressignificações. Junto a isso, essa proposição potencializa o protagonismo estudantil, pois permite "levar o aluno a pensar de forma articulada e contextualizada com sua realidade e fazer com que ele possa ser ator ativo do processo de ensino/aprendizagem" (GIACOMINI; MUENCHEN, 2015, p. 342).

Dessa forma, buscamos, nesta pesquisa, aprofundar e identificar limitações, potencialidades e elementos propositivos centrados em um repensar curricular. Entendemos que a teoria tradicional de currículo, hegemônico nas instituições de ensino, não atende às reais necessidades e demandas socioeducacionais marcadas pela formação crítica, autônoma e criativa, pois "mantêm conhecimentos superados, fora da validade e resistem à incorporação de indagações e conhecimentos vivos, que vêm da dinâmica social e da própria dinâmica do conhecimento" (ARROYO, 2013, p. 37). Assim, é nosso dever, enquanto educadores e pesquisadores, "abrir os currículos com novos conhecimentos e garantir o seu próprio direito e o dos alunos à rica, atualizada e diversa produção de conhecimento e de leituras e significados" (p. 37).

Dessa forma, tomamos como referência a estruturação de um currículo fundamentado pelas teorias críticas e pós-críticas, de constituição identitária e dinamizadas com base em temas. Optou-se pela articulação ciência, cultura e arte como motivação para o exercício curricular. Essa escolha se deu pelo potencial significativo, interdisciplinar e contextual que essas articulações possuem, além de permitir diálogos e visibilidade para uma perspectiva sociocultural, em geral negligenciada no currículo de Ensino de Ciências. Um diálogo entre ciência e arte possibilita olhar as diversidades culturais e identitárias que constituem a nossa sociedade, potencializando uma formação mais humana e que respeita as diferenças, aspectos essenciais para a construção de uma sociedade mais receptiva às mudanças. As articulações ciência, cultura e arte sinalizam, portanto, um caminho possível para repensar o currículo, além de possibilitar finalidades educacionais mais amplas para um projeto de construção identitário diverso, marcado pela diversidade sociocultural da realidade brasileira.

Como contribuição ao exercício de repensar e sistematizar o currículo, analisamos trabalhos que discutem a aproximação ciência, cultura e arte. Dentre os aspectos comuns entre eles, destaca-se a interdisciplinaridade. Mesmo não sendo possível estabelecer uma teoria absoluta que dê conta de explicar como ela pode tomar forma, uma coisa é nítida: ela é categoria de ação (FAZENDA, 2012). Cabe aos educadores, portanto, optarem pela perspectiva de trabalho mais possível para o desenvolvimento de práticas interdisciplinares, pois há uma diversidade de possibilidades. Em se tratando deste trabalho, que é de repensar o currículo, a abordagem temática aparece como direção interessante para a estruturação e a efetivação de uma prática interdisciplinar. Neste sentido, apresentamos, principalmente, dois encaminhamentos: um voltado para um mapeamento curricular, evidenciando caminhos e delineamentos possíveis para uma perspectiva sociocultural, e, outro, uma proposta fundamentada pelos Atos do Teatro como inspiração para a dinamização dos conhecimentos. Afinal, o planejar e o sistematizar aproxima as mudanças que se almeja. Em outras palavras, o querer mudar implica uma mediação teórico-metodológica para vislumbrar a possibilidade (caminhos) de realizar uma determinada ação (VASCONCELLOS, 2012). 
É na dinamização e articulação de conhecimentos interdisciplinares das proposições apresentadas, no entanto, que se encontra a principal limitação deste trabalho e que evidencia um dos grandes desafios educacionais. A interdisciplinaridade envolve respeito às especificidades, mas não a exclusão de ciências ou predominância de algumas. Esta tarefa, todavia, torna-se mais viável numa perspectiva coletiva de troca e construção do conhecimento entre professores da mesma área e áreas distintas; perspectiva que se apresenta como desafio, pois os professores precisam estar abertos para dialogar, em alguma medida, com o outro campo de saber, para, assim, construir a interdisciplinaridade como elemento mediador do deslocamento de um campo para o outro. Pensar um currículo fundamentado em temas exige um olhar atento ao diálogo e à construção interdisciplinar. Esse currículo e dinamização dos conhecimentos, porém, ficarão fragilizados caso o olhar seja reduzido a uma dada área, pois essa simplificará o entendimento e a ressignificação da temática. Dessa maneira, assumimos a limitação nas configurações apresentadas em virtude da área de atuação e formação das autoras, apesar de uma busca por um exercício interdisciplinar.

Enfim, é difícil afirmar o que é currículo, pois cada teoria, tradicional ou não, irá gerar sua definição, mas, de modo comum, o que se apresenta é que ele é caminho, a organização de um processo educativo que explicita diferentes objetivos, estes alinhados com a sociedade em que vivemos e as transformações que almejamos, resultando em disputas e conflitos que se materializam em sala de aula, na práxis docente e na identidade dos sujeitos. Esta análise, no entanto, não é neutra tampouco aleatória; ela deriva das discussões atuais de currículo, cujo enfoque está nas relações entre currículo, cultura e poder, reflexo das teorias críticas e pós-críticas, demonstrando que, mesmo um campo sensível às mudanças, como o currículo, sofre influências das perspectivas teóricas contemporâneas (MOREIRA; TADEU, 2018).

Assim, trabalhar com o campo curricular e efetivar novas configurações não são tarefas fáceis, tendo em vista os imbricados com intencionalidades, propósitos e racionalidades. Dessa maneira, este trabalho buscou dar visibilidade para a necessidade de repensar o currículo, em especial no Ensino de Ciências, que, tradicionalmente, é marcado por uma ênfase disciplinar e de epistemologia das ciências de referência, aspectos que contribuíram para um ensino dissociado da realidade e do endosso à concepção propedêutica (WATANABE; KAWAMURA, 2017). Repensar o currículo, de acordo com os pressupostos discutidos neste trabalho, portanto, tende a contribuir para a aproximação do conhecimento escolar com a realidade vivenciada em busca de uma formação mais humana e cidadã, pois questões, em geral negligenciadas no pensar/fazer currículo, como "o quê?" e "por que ensinar", passam a fazer parte do processo, sinalizando caminhos para a construção e definição de propósitos socioeducacionais mais ampliados.

\section{REFERÊNCIAS}

ALAMBERT, F. Para uma história (social) da arte brasileira. In: BARCINSKI, F. B. (org.). Sobre a arte brasileira: da pré-história aos anos 1960. São Paulo: Editora WMF Martins Fontes, 2014. p. 6-20.

ALCANTARA, M. C.; BRAGA. Elementos histórico-culturais para o ensino dos instrumentos ópticos. Caderno Brasileiro de Ensino de Física, Florianópolis, v. 34, n. 1, p. 109-130, 2017.

ARROYO, M. G. Currículo, território em disputa. Petrópolis, RJ: Vozes, 2013. 
AZEVEDO, L. M S.; BARBOSA-LIMA, M. C., QUEIROZ, G. P. A interdisciplinaridade entre física e arte: o barroco e o modernismo em uma aula de ciências. In: SIMPÓSIO NACIONAL DE ENSINO DE FÍSICA, 17., 2007. Rio de Janeiro. Atas [...]. Rio de Janeiro: Universidade Estadual do Rio de Janeiro, 2007.

CACHAPUZ, A. F. Arte e ciência no ensino das ciências. Interacções, n. 31, p. 95-106, 2014.

COLI, J. O que é arte. São Paulo, SP: Editora Brasiliense, 1995.

CURCIO, I. F. Cor luz - cor pigmento - física e as artes. 2013. Tese (Doutorado em Educação, Arte e História da Cultura) - Universidade Presbiteriana Mackenzie, São Paulo, 2013.

DELIZOICOV, D.; ANGOTTI, J. A.; PERNAMBUCO, M. M. Ensino de ciências: fundamentos e métodos. São Paulo: Cortez, 2011.

DUCHEIKO, L. L.; SILVA, J. A. P. As relações interdisciplinares entre Artes visuais e física/astronomia: um olhar nas culturas indígenas e a questão da transposição didática. Revista Brasileira de Ensino de Ciência e Tecnologia, Curitiba, v. 10, n. 2, p. 1-16, 2017.

FAZENDA, I. C. A. Interdisciplinaridade: história, teoria e pesquisa. Campinas, SP: Papirus, 2012.

FERNANDES, R. F. A. M.; PIRES, F. F.; FORATO, T. C. M.; SILVA, J. A. Pinturas de Salvador Dalí para introduzir conceitos de Mecânica Quântica no Ensino Médio. Caderno Brasileiro de Ensino de Física, Florianópolis, v. 34, n. 2, p. 509-529, 2017.

FERREIRA, F. C. Arte: aliada ou instrumento no ensino de ciências? Revista Arredia, Dourados, v. 1, n. 1, p. 1-12, 2012.

FERREIRA, M. V.; MUENCHEN, C.; AULER, D. Desafios e potencialidades em intervenções curriculares na perspectiva da abordagem temática. Revista Ensaio - Pesquisa em Educação em Ciências, v. 21, p. 1-21, 2019.

GIACOMINI, A.; MUENCHEN, C. Os três momentos pedagógicos como organizadores de um processo formativo: algumas reflexões. Revista Brasileira de Pesquisa em Educação em Ciências, v. 15, n. 2, p. 339355, 2015.

GERHARDT, T. E.; SILVEIRA, D. T. (org.). Métodos de pesquisa. Porto Alegre, RS: Editora da UFRGS, 2009.

GOODSON, I. F. Currículo: teoria e história. Petrópolis, RJ: Vozes, $2013 a$.

GOODSON, I. F. As políticas de currículo e de escolarização: abordagens históricas. Petrópolis, RJ: Vozes, 2013b.

GOMES, T. C.; DI GIORGI, C. A. G.; RABONI, P. C. A. Física e pintura: dimensões de uma relação e suas potencialidades no ensino de física. Revista Brasileira de Ensino de Física, São Paulo, v. 33, n. 4, p. 1-10, 2011.

GORRI, A. P.; SANTIN FILHO, O. Representação de temas científicos em pinturas do século XVIII. Química Nova na Escola, São Paulo, v. 31, n. 3, p. 184-189, 2009.

LABURÚ, C. E.; NARDI, R.; ZÔMPERO, A. F. Função estética dos signos artísticos para promover processos discursivos em sala de aula: uma aplicação durante o ensino do conceito de energia mecânica. Investigações em ensino de ciências, Porto Alegre, v. 19, n. 2, p. 451-463, 2014.

LEABHART, T. (ed.). Mime Journal: Etienne Decroux 80th Birthday, n. 7-8. Allendale - MI (USA): The Performing Arts Center, 1978.

LIMA, L. G.; RICARDO, E. C. Física e literatura: uma revisão bibliográfica. Caderno Brasileiro de Ensino de Física, Florianópolis, v. 32, n. 3, p. 577-617, 2015.

LISBOA, E. A.; BEJARANO, N. R. R. Interdisciplinaridade na formação do professor de física: pesquisas recentes. In: ENCONTRO NACIONAL DE PESQUISA EM EDUCAÇÃO EM CIÊNCIAS, 10., ENPEC, 9., 2013, Águas de Lindóia, SP. Anais [...]. Rio de Janeiro, RJ: Abrapec, 2013.

MARQUES, L. R.; RAZUCK, R. C. S. R. Fotografia no ensino de química: uma proposta didática no contexto da socioeducação. Brasília: Universidade de Brasília, 2016. Vol. 11.

MOREIRA, A. F.; TADEU, T. (org.). Currículo, cultura e sociedade. São Paulo: Cortez, 2018.

MOZENA, E. R.; OSTERMANN, F. Dialogando sobre a interdisciplinaridade em Ivani Catarina Arantes Fazenda e alguns dos integrantes do Grupo de Estudos e Pesquisa em Interdisciplinaridade da PUC-SP (Gepi). Revista Interdisciplinaridade, n. 10, p. 95-107, 2017.

OLIVEIRA, R. D. V. L.; RODRIGUES, L.; QUEIROZ, G. R. P C. Álvaro de Campos, poeta e engenheiro: a utilização de poemas de Fernando Pessoa como recurso didático em aulas de ciência com enfoque em CTS. Interaç̧ões, Santarém, v. 31, p. 107-123, 2014.

REIS, J. C.; GUERRA, A.; BRAGA, M. Ciência e arte: relações improváveis? História, Ciências, Saúde, Manguinhos, v. 13, p. 71-87, 2006. 
RIBEIRO, J. L. P. Arquitetura óptica: análise de um modelo de associação de espelhos cilíndricos como representação dos prédios da Procuradoria Geral da República. Caderno Brasileiro de Ensino de Física, Florianópolis, v. 32, n. 3, p. 837-855, 2015.

SILVA, T. T. Documentos de identidade: uma introdução às teorias do currículo. Belo Horizonte: Autêntica, 2014.

SILVA, M. D. Ciência e arte em sala de aula: mediações possíveis entre arte urbana, Joseph Wright e o ensino de óptica geométrica. 2015. Dissertação (Mestrado Profissional em Ensino de Ciências) - Universidade Tecnológica Federal do Paraná, Curitiba, Brasil, 2015.

STRIEDER, R. B.; CARAMELLO, G. W.; HALMENSCHLAGER,K. R.; FEISTEL, R. A. B.; GEHLEN, S. T. Abordagem de temas na pesquisa em educação em ciências: pressupostos teórico-metodológicos. In: ENCONTRO NACIONAL DE PESQUISA EM EDUCAÇÃO EM CIÊNCIAS, 7., ENPEC, 7., 2011, Campinas, SP. Anais [...]. Rio de Janeiro, RJ: Abrapec, 2011.

VASCONCELLOS, C. S. Planejamento: projeto de ensino-aprendizagem e projeto político-pedagógico. São Paulo: Libertad Editora, 2012.

VELASQUEZ, F. Concepções de cultura na aprendizagem em física: das perspectivas educacionais às representações dos alunos. 2014. Dissertação (Mestrado em Ensino de Ciências) - Universidade de São Paulo, São Paulo, Brasil, 2014.

ZANETIC, J. Física e arte: uma ponte entre duas culturas. Pro-Posições, Campinas, v. 17, n. 1, p. 39-57, 2006.

WATANABE, G.; KAWAMURA, M. R. D. Abordagem temática e conhecimento escolar científico complexo: Organização temática e conceitual para proposição de percursos abertos. Investigações em Ensino de Ciências, Porto Alegre, v. 22, n. 3, p. 145-161, 2017. 